DOI: https//doi.org/10.13037/ci.vol22n49.7371

\title{
Planejamento estratégico em comunicação digital: apontamentos e possibilidades entre a teoria e a prática
}

Strategic planning for digital communication: notes and possibilities between theory and practice

Issaaf Karhawi ${ }^{a}$

ORCID: http://orcid.org/0000-0001-9907-0129

Carolina Frazon Terra ${ }^{b}$

ORCID: http://orcid.org/0000-0003-4016-3747

Recebido em: 24/09/2020. Aprovado em: 26/03/2021.

Resumo

$\mathrm{O}$ artigo tem o objetivo de refletir acerca do planejamento estratégico a partir de conceitos teóricos e práticos e propor etapas para o planejamento em comunicação digital. O texto é resultado do questionamento das autoras em relação às matrizes de planejamento existentes com fins de chegar a um modelo "aberto" que possa ser adaptado e "moldado" de acordo com a necessidade de quem o aplica. A metodologia fundante da proposta é a pesquisa bibliográfica.

Palavras-chave: Planejamento estratégico. Comunicação digital. Etapas.

\begin{abstract}
The article aims to reflect on strategic planning based on theoretical and practical concepts. It also proposes steps for planning for digital communication. The article is the result of authors' questioning of traditional planning matrices to arrive at an "open" model that could be adapted and "shaped" according to the needs of those who apply it. The main methodology is bibliographic research.
\end{abstract}

Keywords: Strategic planning. Digital communication. Stages.

\section{Introdução}

Faz-se necessário, nos dias de hoje, discutir a quase obrigatoriedade de presença digital das organizações com fins de garantir boa visibilidade e relacionamento. Visibilidade se faz crucial, uma vez que tanto organizações quanto indivíduos, pessoas comuns ou influenciadores digitais, operam na necessidade de estarem visíveis para se diferenciarem e atingirem suas audiências. E relacionamento transformou-se em um

\footnotetext{
${ }^{a}$ Universidade de São Paulo - Escola de Comunicação e Artes (ECA/USP). São Paulo/Brasil. E-mail: issaaf@gmail.com

b Faculdade Cásper Líbero. São Paulo/Brasil. E-mail: contato@carolterra.com.br
} 
conceito-chave: sempre foi a base das ações de Relações Públicas, mas, agora, é ponto de partida para qualquer ente que precise dialogar no digital: seja uma marca seja um agente individual. Relacionar-se é estratégico. Abarca não só estar visível, como também interagir, engajar-se, atender, responder, ouvir e absorver tais insights nas estratégias de comunicação. Com isso, o planejamento de mídias sociais se torna condição sine qua non para a presença, engajamento, relacionamento, exposição e visibilidade organizacionais.

Este trabalho surge de uma constatação das autoras: ainda que haja ampla diversidade de trabalhos que versem sobre planejamento estratégico em Comunicação Digital, os discentes dos cursos de graduação e pós-graduação, muitas vezes, recorrem a referências do mercado para produzir planos de comunicação ou Trabalhos de Conclusão de Curso. Apesar da importância desse saber, este artigo surge como resposta a esse movimento ao identificar que a busca por esse tipo de referência se dá pela aparente objetividade e atualidade dos materiais oferecidos pelo mercado. Desse modo, este artigo tem como objetivo apresentar uma sugestão de percurso para o planejamento em Comunicação Digital. Também está no escopo do artigo a estruturação das etapas de planejamento estratégico de comunicação digital a partir da reflexão teórica. De forma prática, pretende contribuir com alunos e profissionais do mercado da Comunicação, de forma mais ampla, e Relações Públicas, na elaboração de planos de comunicação. Vale destacar que nossa pretensão não é a de mapear todos os modelos de planejamento de comunicação digital existentes no mercado ou na academia, mas sim o de refletir acerca dessa temática, propondo um percurso possível para que aconteça, levando-se em consideração aspectos teóricos e práticos.

Para tal, a metodologia na qual o artigo se baseia é uma revisão bibliográfica do tema, assim como uma pesquisa exploratória de discussões práticas que ajudam na identificação de novas perspectivas para o planejamento de comunicação digital. Essa reunião de perspectivas permitiu a construção das etapas do planejamento para que, ao final, pudéssemos sugerir práticas e reflexões para profissionais de Comunicação que necessitem de aportes de planejamento específicos para o campo digital.

\section{A relação entre marcas e públicos permeada pelo digital}

Para iniciarmos o tópico, vale colocarmos a visão de Kunsch $(2018$, p. 16) acerca das organizações contemporâneas e da necessidade de se sistematizar a comunicação organizacional: 
As organizações de todos os tipos estão descobrindo que seus relacionamentos não podem ser apenas com os públicos-alvo do negócio, por meio da comunicação mercadológica. Como parte integrante do sistema social, elas se conscientizam de que têm responsabilidades e compromissos que vão além da fabricação de produtos e da prestação de serviços, com vistas à obtenção de lucros. E isso implica que se posicionem institucionalmente, mediante ações comunicativas planejadas estrategicamente.

Ter ações de comunicação estratégica planejadas passa por gerir regimes de visibilidade, traçar estratégias de relacionamento de uma organização com suas audiências de interesse e programar sua exposição e sua presença no ambiente digital.

A condição de estar visível e saber gerenciar a visibilidade na rede são fundamentais para ganhar destaque na cena digital. É preciso saber trabalhar as "armas" (leiam-se tipos de mídias) - pagas, espontâneas ou gratuitas - que permitam à organização ser vista por sua audiência de maneira destacada e positiva. E isso só se dá com um planejamento de comunicação pensado estrategicamente para aquela determinada organização, marca, produtos e serviços.

Recuero (2009, p. 108) avalia que as plataformas de mídias sociais permitem aos atores sociais estarem mais conectados:

Isso significa que há um aumento de visibilidade social desses nós. A visibilidade é constituída enquanto um valor porque proporciona que os nós sejam mais visíveis na rede. Com isso, um determinado nó pode amplificar os valores que são obtidos através dessas conexões, tais como o suporte social e as interações.

E a autora complementa: "A visibilidade, assim, é um valor por si só, decorrente da própria presença do ator na rede social. Mas ela também é matéria-prima para a criação de outros valores [...]”' (RECUERO, 2009, p. 109). Já para Saad Corrêa (2016, p. 21):

Estar visível nas redes digitais parece ser um mantra da contemporaneidade para pessoas, marcas e toda expressão comunicativa gerada pelas conexões digitais. Com o predomínio de plataformas sociais e dos apps que incentivam a mobilidade participativa, personalizada, geolocalizada e oportunizada de quem possui algum dispositivo conectado à rede, assistimos a um exercício (e quase a uma batalha) coletivo de captura das atenções e, principalmente dos cliques e viewability de todos nós.

Mais do que visibilidade e fórmulas de sucesso para tornar um conteúdo viral, é preciso saber se relacionar, atender, responder, dar retorno à audiência. Sobre isso, Barichello (2017, p. 103) confirma o nosso pensamento: "Não basta estar visível, é 
preciso interagir. A questão colocada hoje é a ampliação das possibilidades interativas entre os sujeitos e a multiplicidade de fluxos de comunicação".

Sobre a questão da mudança da dinâmica organizacional em função da interação e do contexto digital, Kunsch (2018, p. 17) afirma:

As pessoas que se comunicam entre si, por meio de processos interativos, viabilizam o sistema funcional para sobrevivência e consecução dos objetivos organizacionais em um contexto de diversidades, conflitos e transações complexas sob os impactos provocados pela revolução digital. Consequentemente, o modo de produzir e de veicular as mensagens institucionais também passa por profundas transformações. Essa nova dinâmica de processamento de informações e da comunicação na era digital altera completamente as formas de relacionamentos e o modo de produzir a comunicação. Tudo isso provoca profundas transformações no ambiente organizacional e coloca em xeque a visão e a classificação tradicional de ver a comunicação tão somente como transmissão de informações e como simples fator estratégico para alavancar negócios.

Portanto, é preciso ir além de encarar as mídias sociais como simples canais de difusão de informações. Nas palavras de Cipriani (2014, p. 20), "as empresas veem nas mídias sociais meramente uma mídia, e não uma plataforma de relacionamento, diálogo, conversação com o mercado". Para isso, entender qual é a vocação da organização; quais são seus objetivos; que tipo e forma de conteúdo são mais adequados à audiência que se quer atingir; que métricas, índices e parâmetros serão usados etc. são cruciais para se planejar a atividade nas plataformas de mídias sociais de maneira estratégica, exitosa e com efetivo retorno. E isso passa por definir um planejamento de comunicação digital que consiga dar um caráter estratégico à organização.

\section{Planejamento estratégico em comunicação digital}

Sobre planejamento estratégico de comunicação ${ }^{\mathrm{a}}$, temos autores consagrados, sobretudo na área de Relações Públicas, a exemplo de Margarida Kunsch. A autora estuda, desde o final da década de 1980, como o planejamento de comunicação é crucial para as organizações que querem construir suas imagens e reputações - positivas - a fim de angariar outros objetivos, que não só os de construção de boa vontade dos públicos em

\footnotetext{
a Como posto, não foi objetivo deste artigo fazer um resgate histórico acerca do planejamento estratégico. Sabemos de suas bases tanto no campo da Administração quanto da Comunicação. Especificamente, para este último, o livro Planejamento de Relações Públicas na Comunicação Integrada (KUNSCH, 2016) faz o papel de mapear conceitos de planejamento, reuni-los, discuti-los e ainda propõe um modelo direcionado à comunicação no contexto das organizações. Assim, o intuito do nosso artigo é partir para uma proposta específica para o ambiente digital e para as necessidades dos profissionais de comunicação.
} 
relação a elas, mas também com finalidade mercadológica e de contentamento interno. Porém, alerta:

A visão predominante de comunicação estratégica é comumente mais centrada nos resultados pragmáticos das ações comunicativas. Ignora a complexidade e as incertezas do ambiente, partindo do pressuposto de que um bom planejamento estratégico é capaz de alcançar os resultados desejados e promover uma comunicação eficaz (KUNSCH, 2018, p. 14).

É preciso ir além dos itens a serem cumpridos em um planejamento. Uma das atribuições do profissional de comunicação contemporâneo passa pela leitura das complexidades que envolvem os ambientes internos e externos à organização, questões de contexto, cultura, entre outros aspectos.

Aplicando o conceito de planejamento de comunicação às ambiências digitais, dentre os autores que abordam a temática, destacamos Elizabeth Saad Corrêa (2005, 2009) que defende a necessidade de presença das organizações nos meios digitais de maneira estruturada, sistemática e estratégica. E, é nesse sentido, que a definição de etapas do planejamento se faz necessária.

\section{Etapas do planejamento estratégico em comunicação digital}

Como mencionado, o objetivo deste artigo é apresentar uma possibilidade sistematizada para o planejamento em comunicação digital. Para além das discussões em Relações Públicas e Comunicação Organizacional, essa proposta pode contemplar áreas diversas que lidam diretamente com a construção de presença, relacionamento e posicionamento on-line.

Desse modo, com base na experiência docente e profissional das autoras, propomos etapas para o planejamento estratégico em comunicação digital que contemplem os seguintes pontos: monitoramento da reputação da organização, identificação do público, análise de concorrentes, objetivos de comunicação, seleção de mídias digitais, produção de conteúdo relevante, mensuração e análise de resultados. 
Figura 1 - Etapas do planejamento em Comunicação Digital

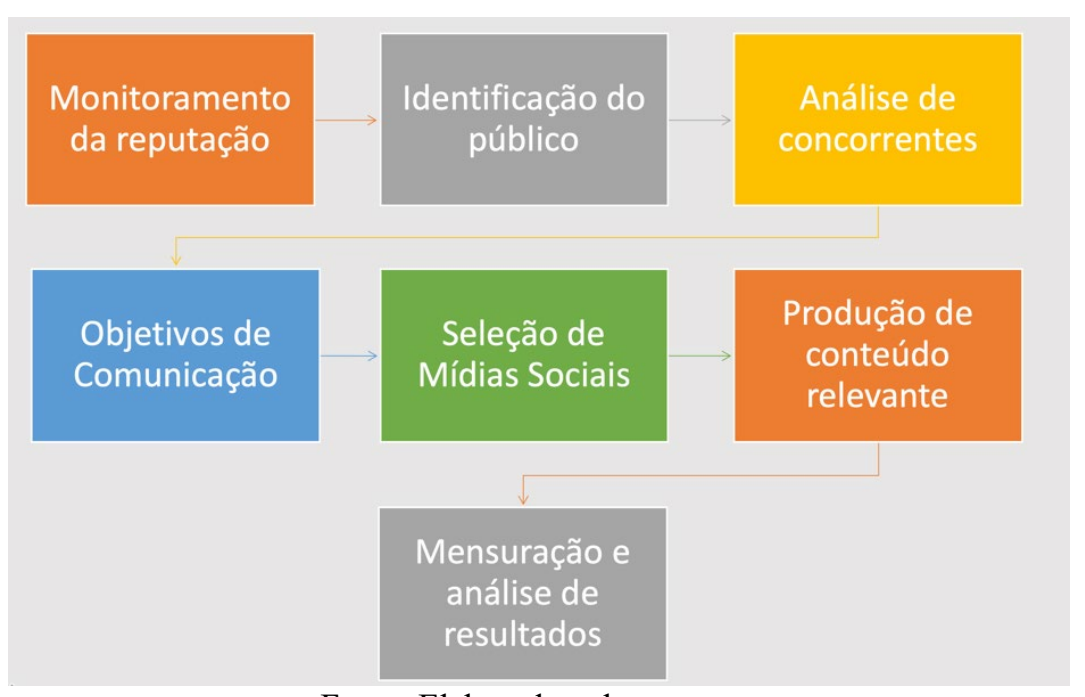

Fonte: Elaborado pelas autoras.

A justificativa para a inserção de cada etapa e ferramenta no planejamento, as possibilidades táticas e discussões teóricas serão abordadas ao longo do presente trabalho.

\subsection{Monitoramento da reputação}

O monitoramento ocupa o primeiro lugar no planejamento estratégico em comunicação digital. Isso porque ele permite compreender quais são as percepções do público em relação a uma organização, marca ou figura pública. Para Boarini, o monitoramento deve ser usado para avaliar a influência das organizações. Mais especificamente, a ferramenta torna "[...] possível verificar interações com menção à marca, positivas e negativas, [e] frequência” (BOARINI, 2016, p. 79). Influência positiva essa que, como lembra a autora, "[...] decorre de um processo prévio de conquista de confiança” (BOARINI, 2016, p. 69).

Por sua vez, Silva afirma que um dos objetivos do monitoramento é identificar e analisar os sentimentos, desejos e reações dos públicos em relação a uma organização, marca ou produto. Para tal, o monitoramento atua com a "coleta, armazenamento, classificação, categorização, adição de informações e análise de menções on-line públicas a determinado(s) termo(s) previamente definido(s) e seus emissores" (SILVA, 2012, p. 41-42).

Sendo assim, o monitoramento assemelha-se, de certo modo, com a etapa de diagnóstico do planejamento tradicional em Relações Públicas. O diagnóstico, grosso modo, serve para a identificação de situações que afetam o posicionamento e a imagem 
da organização (Lopes e Penafieri, 2016) e deve responder a questões como: "o que é fonte do problema, onde está a fonte, quando o problema ocorre, quem está envolvido ou é afetado por ele, como esses públicos são envolvidos ou afetados e por que o tema relacionado ao cenário interessa à organização e a seus públicos" (LOPES; PENAFIERI, 2016, p. 109).

As autoras prosseguem afirmando que "o monitoramento do ambiente e o detalhamento da situação-problema podem ser conduzidos por meio do levantamento de dados secundários, ou seja, pela coleta de dados pré-existentes" (LOPES; PENAFIERI, 2016, p. 109). Ainda que o termo "monitoramento" seja amplamente usado mesmo antes das ferramentas digitais, o que apresentamos aqui guarda particularidades:

1) $\mathrm{O}$ monitoramento em redes sociais, especificamente, pode ser feito por meio de ferramentas pagas ou gratuitas ou de forma manual ${ }^{\mathrm{b}}$. O objetivo é extrair das redes sociais digitais menções (comentários, posts, publicações) que usem um termo previamente definido na busca (como o nome da organização ou marca a qual o planejamento servirá). Cada menção, posteriormente, é analisada e categorizada em positiva, negativa ou neutra. O parâmetro de classificação deve ser definido pela organização ou equipe responsável pelo monitoramento. Ao final do trabalho, tem-se um resultado da "saúde da organização" nas redes sociais digitais.

2) O monitoramento digital também pode ser feito por meio da identificação de tendências de busca. Plataformas gratuitas como o Google Trends ${ }^{c}$ ou Answer The Public ${ }^{\mathrm{d}}$ permitem perceber a oscilação no interesse dos usuários por termos específicos. Ainda que não haja contato com os sentimentos dos públicos, diretamente, o monitoramento de tendências permite reconhecer movimentos de mercado valiosos para o planejamento.

\footnotetext{
${ }^{\mathrm{b}}$ Durante a escrita deste trabalho, as ferramentas Scup, e-life, Zeeng, Sprinkrl, LiveBuzz, entre tantas outras, podem ser citadas como exemplos de ferramentas pagas de monitoramento. Já a coleta manual pode ser feita por meio de hashtags ou buscadores das próprias redes sociais.

${ }^{c}$ Há opções que auxiliam no sentido de busca de palavras-chave, como Übersuggest, SEMRush, Keyword Tool, Alexa, Moz, WordStream, entre outras.

d Disponível em: https://answerthepublic.com/ . Acesso em 24/02/2021.
} 


\subsection{Identificação do público}

Uma consequência do monitoramento é a identificação dos públicos. Ainda que haja uma discussão clássica e aprofundada acerca dos públicos em Relações Públicas ${ }^{\mathrm{e}}$, aqui, valemo-nos da posição da autora Dreyer (2017, p. 53):

[...] o profissional de relações públicas, ao planejar a comunicação, poderá ter certa dificuldade por ter de incluir um "novo" público [do digital], atuante e diferente do tradicional, em suas estratégias, mas ganha na facilidade de poder dialogar, relacionar-se e entender o que ele pensa a respeito da empresa

Essa facilidade mencionada pela autora se revela no uso de ferramentas de monitoramento, por exemplo, que permitem - por meio da coleta de menções públicas a apreensão de características do público em questão. Assim, é possível identificar as comunidades de interesse digitais nas quais os públicos da organização se articulam, sobre quais temas publicam nas redes sociais digitais, quem são os influenciadores que acompanham e quais marcas, entre as concorrentes, consomem midiaticamente.

\subsection{Análise de concorrentes}

A análise de concorrentes no planejamento em comunicação digital não busca, como de praxe, "[...] descobrir o que impulsiona o concorrente mais significativo, quais são seus planos de expansão, e o que ele está buscando no mercado" (YANAZE, 2011, p. 167). Espera-se que essa etapa do planejamento seja prévia à entrada da organização no digital, uma vez que contempla estratégias de negócio. Assim, a análise de concorrentes proposta neste artigo tem como benefício a "identificação de algumas questões estratégicas, que devem ser monitoradas ao longo do tempo" (YANAZE, 2011, p. 168).

Essas questões estão relacionadas à identificação dos objetivos de comunicação dos concorrentes nas mídias digitais, avaliação dos principais indicadores e métricas da concorrência; mapeamento do tipo de conteúdo produzido pela organização e tipo de relacionamento estabelecido com os públicos. Para o profissional de mídias digitais, cabem questionamentos temáticos:

\footnotetext{
e Públicos internos, externos e mistos (França, 2012); públicos de decisão, consulta, comportamento e opinião (SIMÕES, 1995); Não público, público latente, público consciente e público ativo (GRUNIG; HUNT apud FRANÇA 2012).
} 
1) Sobre gestão dos públicos: como é feita a gestão de relacionamento e atendimento dos concorrentes nas mídias digitais? Que tipo de conversações são estabelecidas? A organização se coloca de forma mais reativa ou pró-ativa na relação? Como são tratadas as reclamações, sugestões, elogios e críticas?

2) Sobre conteúdo: que tipo de conteúdo é publicado pelos concorrentes? Qual a frequência, formato e assunto das publicações? Quais parecem ser os objetivos na construção de presença digital da marca concorrente analisada? Que conteúdos tiveram uma boa performance e suscitaram interação?

3) Sobre métricas e indicadores: quais são as principais métricas da concorrência? Quais delas podem ser usadas como parâmetros para o sucesso ou fracasso do planejamento em desenvolvimento?

\subsection{Objetivos de comunicação}

As etapas do planejamento até aqui fornecem um material para o profissional e a organização que permite reconhecer o lugar que a marca ocupa no ambiente digital e na rotina dos públicos e do mercado, de forma mais ampla. Parte-se, portanto, para um momento de definição dos objetivos estratégicos da organização no digital.

Aqui, vale ressaltar que a definição de objetivos é etapa crucial em um planejamento: “[...] objetivo é a especificação dos resultados esperados pela organização, a explicitação de onde se pretende chegar e do que se espera alcançar por meio da comunicação" (YANAZE; FREIRE; SENISE, 2013, p. 81). A partir de uma perspectiva mais alinhada ao digital, Cipriani afirma que "muitos dos benefícios comumente relacionados ao uso de mídias sociais acabam sendo convertidos em objetivos estratégicos [...]" (2014, p.114). E, assim, o autor define quatro grandes objetivos estratégicos para a comunicação digital, sendo:

Relacionamento e proximidade com o cliente, fornecedores, parceiros de negócio e até mesmo competidores. Percepção da marca no mercado e na sua base de clientes atual. Inovação e criatividade nos produtos e serviços, modelos de negócio, processos internos e abordagens de marketing. Eficiência e efetividade das operações da empresa, cumprindo processos com o melhor uso de recursos possível, reduzindo custos, otimizando o tempo e aumentando o resultado (CIPRIANI, 2014, p. 114, grifos do autor).

Apesar das categorias estanques não serem a única possibilidade de atuação no digital, o autor oferece um pontapé no planejamento estratégico de uma marca. Como 
pode ser visto na Figura 2, os objetivos principais anteriormente apresentados podem se desenrolar em objetos mais específicos.

Figura 2 - Objetivos estratégicos em comunicação digital

\begin{tabular}{|c|c|c|c|}
\hline Percepção da marca & $\begin{array}{l}\text { Relacionamento e } \\
\text { proximidade }\end{array}$ & $\begin{array}{l}\text { Inovação e } \\
\text { criatividade }\end{array}$ & $\begin{array}{l}\text { Eficiência e } \\
\text { efetividade }\end{array}$ \\
\hline $\begin{array}{l}\text { Aumentar a } \\
\text { reputação da marca }\end{array}$ & $\begin{array}{l}\text { Aumentar a fidelidade } \\
\text { do cliente }\end{array}$ & $\begin{array}{l}\text { Trazer ideias de fora } \\
\text { da empresa }\end{array}$ & $\begin{array}{l}\text { Melhorar a qualidade } \\
\text { das relações públicas }\end{array}$ \\
\hline $\begin{array}{l}\text { Ampliar a percepção } \\
\text { da marca }\end{array}$ & $\begin{array}{l}\text { Melhorar o } \\
\text { relacionamento com } \\
\text { parceiros de negócios }\end{array}$ & $\begin{array}{l}\text { Potencializar o sucesso } \\
\text { de novos produtos }\end{array}$ & $\begin{array}{l}\text { Reduzir os custos de } \\
\text { pesquisas de } \\
\text { marketing }\end{array}$ \\
\hline $\begin{array}{l}\text { Criar vantagem } \\
\text { competitiva }\end{array}$ & $\begin{array}{l}\text { Aumentar a captura } \\
\text { de oportunidades de } \\
\text { venda }\end{array}$ & $\begin{array}{l}\text { Inovar o modelo de } \\
\text { negócios }\end{array}$ & $\begin{array}{l}\text { Reduzir os custos de } \\
\text { aquisição de clientes }\end{array}$ \\
\hline $\begin{array}{l}\text { Gerar mais marketing } \\
\text { boca a boca }\end{array}$ & $\begin{array}{l}\text { Melhorar a qualidade } \\
\text { do suporte ao cliente }\end{array}$ & & $\begin{array}{l}\text { Reduzir os custos de } \\
\text { suporte ao cliente }\end{array}$ \\
\hline $\begin{array}{l}\text { Preparar a empresa } \\
\text { para gestão de crises }\end{array}$ & & & $\begin{array}{l}\text { Identificar talentos } \\
\text { dentro e fora da } \\
\text { empresa }\end{array}$ \\
\hline
\end{tabular}

Fonte: Adaptado pelas autoras a partir de Cipriani, 2014, p. 115.

Nessa etapa do planejamento, acredita-se ser necessária a definição de objetivos que vão guiar não apenas a produção de conteúdo da organização no digital, mas também a mensuração de resultados mais adiante. Além disso, uma vez que não é mais possível dissociar o on e o off-line (SAAD CORRÊA, 2015), os objetivos de comunicação digital devem estar intrinsecamente ligados às estratégias e ações de comunicação em outras mídias.

\subsection{Seleção das mídias sociais}

É apenas após uma profunda autoanálise e um olhar para audiências e concorrência que devemos definir que conjunto de ferramentas digitais nos atende. Sabendo onde está a audiência, o que ela fala, como fala, o que sinaliza e enaltece e como as organizações do segmento/setor se comportam, é que são definidas as plataformas em que a organização estará presente e para a qual fará o plano de conteúdo, presença, engajamento e visibilidade. Sobre o que falam as audiências e de quais plataformas também nos trazem a oportunidade de entender o que pensam os usuários a respeito da organização, seus produtos e serviços. 
Nesse momento, também cabe refletir sobre a compatibilidade e necessidade da organização estar (ou não) em todas as redes sociais digitais ou de compartilhar o meme de sucesso do momento, por exemplo. Apenas as etapas anteriores darão confiança para o profissional de Comunicação fazer escolhas e abrir mão de mídias que possam não auxiliar no planejamento em construção.

\title{
4.6 Produção de conteúdos relevantes
}

Opostamente ao que pode ser compreendido como usual, a produção de conteúdo - os posts em si - é a penúltima etapa do planejamento. Isso porque

\begin{abstract}
A produção de conteúdo para as mídias sociais deve constituir-se em um processo planejado e profissional que leve em conta não apenas os aspectos técnicos associados à construção dos textos propriamente dita (lógica da argumentação, correção gramatical, articulação e precisão das informações etc.), mas a adequação ao perfil do público, às suas demandas e aos seus interesses e o vínculo estreito com os objetivos estratégicos da organização (BUENO, 2015, p. 133)
\end{abstract}

Vale destacar que conteúdo relevante nas mídias digitais é aquele prestador de serviço, que adiciona valor ao cotidiano de quem o consome. Um benchamarking interessante se dá pelos influenciadores digitais e seu modus operandi ligado ao como fazer, aos tutoriais, ao faça-você-mesmo. Conteúdos que inspiram, que auxiliam ou que simplesmente entretêm. Mas, para tal, não se deve perder em vista dois aspectos: perfil do público e tom da organização nas redes.

Nas pesquisas em Marketing, seria possível compreender o perfil do público como buyer persona e o da organização como brand persona. No primeiro caso, é definido um arquétipo de "comprador", "seguidor" reais da marca ou organização. Essa persona é construída a partir de dados demográficos básicos, mas também reflexões sobre os anseios desse seguidor, comprador, admirador da marca passando pelos medos, conflitos, desejos etc. No segundo caso, trata-se de "[...] um recurso utilizado por empresas que buscam se comunicar com seus públicos de forma coerente, com personalidade, tom e características definidas, sem confundir os públicos com estilos diferentes a cada nova mensagem" (SILVA; AMARAL, 2016, p. 189). Ou seja, as duas ferramentas auxiliam na produção de conteúdo, uma vez que a coerência narrativa alcançada resulta em uma percepção mais positiva, por parte dos públicos, em relação à relevância do conteúdo digital da organização. De forma mais específica, a definição do tom da organização, ou de sua brand persona, implica em estratégias de relacionamento mais bem definidas. 
Assim, todo tipo de interação de uma marca com seus públicos terá a mesma lógica argumentativa, senso de humor, tipo de resposta etc.

É importante manter registros desse tom da organização e das personas que caracterizam os públicos. Assim, independente do profissional responsável pela atividade ou o setor com a atribuição de desempenhá-la, será possível prosseguir alinhados ao estabelecido no planejamento.

\subsection{Mensuração e análise dos resultados}

A última etapa do planejamento estratégico em comunicação digital é a mensuração e análise de resultados. Apesar da integração no planejamento, não significa que essa função será desempenhada pelo mesmo profissional.

Para Panella (2007), a mensuração não apenas serve para justificar os investimentos financeiros da organização em determinada ação de Comunicação, mas também para valorizar e melhorar o trabalho realizado. No digital, as métricas auxiliam na etapa de mensuração pois são dados facilmente acessados e coletados.

Nesse sentido, deve-se reconhecer que a definição de métricas e de indicadoreschave de performance (ou key performance indicator, KPIs) está diretamente associada aos objetivos definidos no planejamento. Se uma organização define que sua presença digital está associada ao objetivo de ampliação de percepção de marca, dados relativos ao alcance de publicações seriam indicadores a serem acompanhados. A clareza dos objetivos reflete em mais segurança por parte do profissional no momento da mensuração.

O digital trouxe a lógica da dataficação dos processos midiáticos, os dados visíveis e à disposição trouxeram uma lógica numérica para dentro dos processos de Comunicação. De certo modo, esse movimento pode levar à certa racionalidade econômica (KUNSCH, 2016) e trazer maturidade e profisssionalismo para a atuação digital. Ao mesmo tempo, a busca por métricas sem quaisquer parâmetros ou fundamentos coloca em xeque o resultado efetivo do planejamento e das ações em curso. Há uma discussão no mercado sobre métricas de vaidade ou métricas vazias. No digital, elas se referem aos números mais evidentes nas redes: como total de seguidores ou número de curtidas. Apesar de estarem em um local de cartão postal dos perfis e páginas nas redes sociais, essas métricas só têm valor se alinhadas aos objetivos empresariais da organização. Caso contrário, elas não são suficientes para a mensuração e podem levar a uma pseudoavaliação (GALERANI, 2006). 
Assim, o sucesso ou fracasso de uma campanha no digital deve ser medido a partir dos dados que traduzem os objetivos. O objetivo de captação de novos consumidores só pode ser mensurado a partir de dados de cliques em links, abertura de carrinhos dentro de e-commerces, ativação de cupons de desconto etc. Um objetivo como esse, se for avaliado, por exemplo, a partir do número de comentários em uma publicação não estará sendo, de fato, mensurado.

\section{Considerações finais}

Este artigo teve como objetivo estruturar etapas de planejamento estratégico para a Comunicação Digital, mas sem a pretensão de encerrar ou delimitar o tema. Entendemos que as etapas aqui propostas servem como um direcionador para os profissionais de comunicação, estudantes e pesquisadores da área.

Um dos objetivos do nosso texto era fundir teoria e prática, algo que propusemos ao elaborar um modelo prático de planejamento digital suportado por reflexões, teorias e pensamentos de autores ligados ao campo da Comunicação.

Planejar sempre foi indispensável à prática de Comunicação Organizacional e Relações Públicas, independente do meio (on ou off-line). Portanto, nossa intenção nunca foi a reinvenção de um processo já consolidado na área, mas o de agregar uma possibilidade de realização de planejamento específico para a ambiência digital e suas particularidades, ou seja, com etapas inerentes ao meio.

As etapas acima propostas têm a função de despertar nos leitores reflexões para que apliquem - de maneira adaptada e flexível - em suas realidades de negócio, de setor, de tamanho, de porte e sirvam como um guia norteador, mas sem o objetivo de finalizálo ou restringi-lo. Espera-se que, ao final da leitura, ele possa servir como base para elaboração de planos de Comunicação, mas também como apontamento para outros desdobramentos teóricos e práticos.

\section{Referências}

BARICHELLO, Eugenia M. R. Visibilidade e legitimidade na atual ecologia midiática. Revista Estudos em Comunicação.. v. 2, n. 25, p. 99-108, dez. 2017. Disponível em: http://ojs.labcom-ifp.ubi.pt/index.php/ec/article/view/306/172. Acesso em: 14 set. 2020. 
BOARINI, Dulce Margareth. O planejamento da Comunicação On-line: Como a velocidade no fluxo da informação altera a forma de planejar. Dissertação (Comunicação Social) - Universidade Metodista de São Paulo, 2016.

BUENO, Wilson da Costa. Estratégias de comunicação para as mídias sociais. In: BUENO, Wilson da Costa. (Org.) Estratégias de comunicação nas mídias sociais. Barueri: Manole, 2015. p. 123-144.

CIPRIANI, Fabio. Estratégia em mídias sociais. Rio de Janeiro: Elsevier, 2014.

DREYER, Bianca Marder. Relações públicas na contemporaneidade: contexto, modelos e estratégias. São Paulo: Summus Editorial, 2017.

GALERANI, Gilceana Soares Moreira. Avaliação em Comunicação Organizacional. Brasília: Embrapa, 2006.

KUNSCH, Margarida Maria Krohling. A comunicação estratégica nas organizações contemporâneas, 2018. Revista Media e Jornalismo. Disponível em: https://impactumjournals.uc.pt/mj/article/view/6020/4924 . Acesso em: 07 out. 2019.

KUNSCH, Margarida Maria Krohling. Planejamento de Relações Públicas na Comunicação Integrada. 6. ed. São Paulo: Summus, 2016.

LOPES, Valéria de Siqueira Castro; PENAFIERI, Vânia. Diagnósticos organizacionais: a contribuição da pesquisa em relações públicas. Revista Organicom. v. 13. n.25, 2016. Disponível em: http://www.revistas.usp.br/organicom/article/view/139343. Acesso em: 12 set. 2020

PANELLA, Cristina. Teorizar e medir: a pesquisa na gestão da imagem e da reputação. Revista Organicom. v. 4. n.7, 2007. Disponível em: http://www.revistas.usp.br/organicom/article/view/138957/134305. Acesso em: 12 set. 2020

RECUERO, Raquel. Redes sociais na internet. Porto Alegre: Sulina, 2009.

SAAD CORRÊA, Elizabeth. Comunicação na contemporaneidade: visibilidades e transformações. In: SAAD CORRÊA, E. (Org.). Visibilidade e consumo da informação nas redes digitais. Porto: Media XXI, 2016, p. 19-39.

SAAD CORRÊA, Elizabeth. Centralidade, transversalidade e resiliência: reflexões sobre as três condições da contemporaneidade digital e a epistemologia da comunicação. Anais Ibercom 2015. Disponível em: http://www3.eca.usp.br/sites/default/files/form/biblioteca/acervo/producaoacademica/002736076.pdf. Acesso em: 12 jun. 2020.

SAAD CORRÊA, Elizabeth. A comunicação digital nas organizações: tendências e organizações. Revista Organicom.. Edição Especial. v. 6, n. 10-11, p. 161-167, 2009. Disponível em: http://www.eca.usp.br/departam/crp/cursos/posgrad/gestcorp/organicom/re_vista1011/161.pdf. Acesso em 09 out. 2019. 
SAAD CORRÊA, Elizabeth. Comunicação digital: uma questão de estratégia e de relacionamento com públicos. Revista Organicom. v. 2, n. 3, p. 94-111, 2005. Disponível em: http://www.revistas.usp.br/organicom/article/view/138900/134248. Acesso em: 09 out. 2019.

SILVA, Tarcízio; AMARAL, Yuri. Criando personas e ilustrações. In: Monitoramento e pesquisa em mídias sociais: metodologias, aplicações e inovações. São Paulo: Uva Limão, 2016. p. 187-210.

SILVA, Tarcízio. Monitoramento de Mídias Sociais. In: SILVA, T. Para entender o Monitoramento de Mídias Sociais. São Paulo: Ibpad, 2012. p. 41-45.

YANAZE. Mitsuru Higuchi. Gestão de Marketing e Comunicação - Avanços e Aplicações . 2. ed. Revista e Ampliada. São Paulo: Editora Saraiva, 2011.

YANAZE, Mitsuru Higuchi; FREIRE, Otávio; SENISE, Diego. Retorno de investimento em comunicação: avaliação e mensuração. São Caetano do Sul: Difusão Editora, Rio de Janeiro: Editora Senac, 2013.

\footnotetext{
${ }^{a}$ Issaaf Karhawi é doutora em Ciências da Comunicação pela Escola de Comunicações e Artes da Universidade de São Paulo (ECA-USP) e mestre pela mesma instituição. Atua como pesquisadora em Comunicação Digital no grupo de pesquisa COM+ (ECA-USP). É autora do livro "De blogueira a influenciadora: etapas de profissionalização da blogosfera de moda brasileira", publicado pela Editora Sulina (Coleção Cibercultura). É docente no curso de pósgraduação lato sensu em Mídia, Informação e Cultura do Centro de Estudos Latino-Americanos sobre Cultura e Comunicação (CELACC-USP).

${ }^{\mathrm{b}}$ Carolina Frazon Terra tem pós-doutorado em Ciências da Comunicação, doutorado e mestrado em Interfaces Sociais da Comunicação, e especialização em Gestão Estratégica da Comunicação Organizacional e Relações Públicas, todos pela ECA-USP. É formada em Relações Públicas pela UNESP/Bauru. É atualmente docente na graduação em Relações Públicas e no mestrado da Faculdade Cásper Líbero, e em pós-graduações e MBAs da ECA-USP e FIA. É autora dos livros "Marcas Influenciadoras Digitais", "Mídias Sociais...e agora?" e "Blogs Corporativos", todos pela Difusão Editora.
} 